\title{
PENGEMBANGAN MEDIA PEMBELAJARAN STRUKTUR PERNAPASAN DAN EKSKRESI MANUSIA UNTUK KELAS XI IPA DI SMA NEGERI 2 SINGARAJA
}

\author{
Ketut Putranadi1), Desi Seri Wahyuni2), Ketut Agustini3)
}

Program Studi Pendidikan Teknik Informatika Jurusan Teknik

Singaraja, Bali

E-mail : ketutputranadi10@gmail.com, seri.wahyuni@undiksha.ac.id, ketut.agustini@undiksha.ac.id

\begin{abstract}
Abstrak-Perkembangn teknologi saat ini berpengaruh kepada dunia Pendidikan, salah satunya adalah berdampak pada perkembangan media pembelajaran. Belajar dan media pembelajaran memiliki kaitan yang sangat erat, proses pembelajaran tidak bisa berjalan dengan lancar tanpa adanya media pembelajaran yang tepat. Media pembelajaran yang digunakan di SMA Negeri 2 Singaraja masih menggunakan metode konvensional yaitu metode ceramah dan pembelajaran yang disampaikan oleh guru monoton, sehingga menyebabkan siswa cenderung bosan pada saat proses pembelajaran. Pengembangan media pembelajaran struktur pernapasan dan ekskresi manusia menggunakan model MDLC. Yang terdiri dari enam tahap yaitu Pengonsepan (Concept), Perancangan (Design), Pengumpulan Bahan (Material Collecting), Pembuatan (Assembly), Pengujian (Testing) dan Dsitribusi (Distribution). Media pembelajaran yang tepat merupakan kunci utama agar siswa mampu melakukan pembelajaran dengan semangat dan media pembelajaran ini akan dipadukan dengan konsep gamifikasi yang di akhir pembelajaran terdapat permainan kecil yang akan merefleksi pikiran siswa dengan cara bermain, akan tetapi tidak sedikitpun mengurangi pembahasan materi yang diawal dijelaskan. Terdapat beberapa pengujian untuk mengetahui kelayakan media, terdiri dari uji ahli isi dengan hasil 1 sangat baik, uji ahli media 0.87 sangat baik kemudian uji respon terhadap siswa $82 \%$ sudah memenuhi kriteria baik.
\end{abstract}

Kata kunci: Media Pembelajaran, Gamifikasi, Biologi, MDLC

\begin{abstract}
Technological developments currently affect the world of education, one of which is the impact on the development of learning media. Learning and learning media have a very close relationship, the learning process cannot run smoothly without the right learning media. The learning media used in SMA Negeri 2 Singaraja still uses conventional methods, namely the lecture and learning methods delivered by monotonous teachers, causing students to tend to be bored during the learning process. Development of learning media for human respiratory and excretory structures using the MDLC model. It consists of six stages, namely Concept, Design, Material Collecting, Assembly, Testing and Distribution. The right learning media is the main key so that students are able to do learning with enthusiasm and this learning media will be combined with the concept of gamification which at the end of the lesson there is a small game that will reflect on students' minds by playing, but does not in the slightest reduce the discussion of the material that was explained at the beginning. There are several tests to determine the feasibility of the media, consisting of a content expert test with 1 very good result, a media expert test of 0.87 very good then a response test of $82 \%$ of students who have met good criteria.
\end{abstract}

Keywords: Learning Media, Gamification, Biology, MDLC 


\section{PENDAHULUAN}

Rendahnya kualitas pendidikan di Indonesia secara tidak langsung menunjukkan rendahnya kualitas pembelajaran. Rendahnya kualitas pembelajaran dapat dilihat salah satunya pada mata pelajaran yang memiliki karakteristik materi yang masih abstrak dan kompleks. Guru masih kesulitan mengkonkritkan konsep yang abstrak dan siswa pun susah memahami apa yang disampaikan guru. Kemudian keterbatasan sumber belajar yang tersedia juga belum optimal sehingga belum mendukung proses pembelajaran.

Salah satu inovasi terhadap proses pembelajaran adalah teknologi multimedia. Teknologi multimedia memungkinkan terjadinya penyampaian informasi dengan lebih cepat, interaktif dan menarik (Binanto, 2010). Pemanfaatannya telah diterapkan dalam berbagai bidang, seperti kesehatan, bisnis, hiburan, pendidikan dan berbagai kepentingan umum lainnya. Dalam bidang pendidikan, multimedia menjadi teknologi yang mempermudah proses pembelajaran. Dengan menggunakan multimedia, pengajar dapat menyajikan gambaran benda yang kompleks, berukuran sangat kecil atau sangat besar, serta peristiwa yang berlangsung sangat cepat dan berada di tempat yang jauh dalam bentuk yang menarik. Hal ini bermanfaat dalam meningkatkan imajinasi, pemahaman dan minat pelajar, terutama siswa. Pada kegiatan belajar mengajar konvensional, seorang tenaga pendidik hanya akan memberikan materi pembelajaran kepada siswa dengan buku panduan dan menyampaikan teori. Pada materi yang bersifat abstrak contohnya materi tentang struktur dan fungsi pada sistem pernapasan, Apabila materi yang disampaikan oleh tenaga pendidik tidak mampu diserap oleh siswa, maka akan menyebabkan murid tersebuat salah konsep dan sangat sulit untuk mengerti tentang materi yang diajarkan.

Setelah penulis melakukan konsultasi dengan guru mata pelajaran biologi di kelas XI SMA Negeri 2 Singaraja Yang Bernama Drs. Ketut
Sarah Udaya. Beliau mengatakan bahwa dalam proses pembelajaran biologi media pembelajaran sangat diperlukan, karena proses pembelajaran masih menggunakan metode demonstrasi dalam mengajar. Hal ini menyebabkan proses kegiatan belajar mengajar kurang efektif dan tingkat pemahaman siswa dalam belajar belum sesuai harapan. Selama itu penyajian materi juga masih menggunakan metode konvensional, dan guru sudah menggunakan media seperti gambar gambar terkait materi yang dijelaskan dengan menggunakan gambar tersebut sebagai permasalahan yang harus dipecahkan oleh siswa, padahal dari sisi konten masih abstrak dimana siswa menjadi susah memahami materi abstrak dan sumber bahan ajar masih terbatas. Penyampaian materi struktur pernapasan dan ekskresi manusia tidak didukung dengan adanya fasilitas penunjang pembelajaran sehingga siswa sulit untuk memahami materi pada saat proses belajar mengajar. Dimana hal tersebut menyebabkan siswa cenderung bersikap pasif dalam proses pembelajaran, sehingga hanya sebagai penerima informasi dari guru. Teknologi komputer belum dimanfaatkan untuk proses pembelajaran struktur pernapasan dan ekskresi manusia, sehingga menyebabkan turunnya motivasi dan minat belajar siswa. Terbatasnya pengetahuan guru dalam mengembangkan media pembelajaran interaktif sebagai media guru untuk menyampaikan materi pelajaran.

Dengan demikian perlu adanya pemilihan media pembelajaran yang sesuai dengan kompetensi yang ingin dicapai, karakteristik siswa, kesesuaian antar guru dan siswa, biaya, watu proses pembelajaran, dan hal-hal yang mendukung lainnya. Salah satu pemilihan media pembelajaran yang tepat untuk dapat digunakan dalam pembelajaran yaitu berupa media pembelajaran. Penggunaan media pembelajaran ini diaharapkan mampu meningkatkan semangat belajar siswa dan dapat dijadian sebagai sumber belajar yang mandiri guna mengatasi keterbatasan ruang dan waktu.

Dari permasalahan yang terjadi, penulis dapat memberikan solusi yaitu sebuah media pembelajaran. Media pembelajaran merupakan, sebuah media pembelajaran yang dapat menampilan visual video di dalam sebuah materi 
penerima pesan Prawiradilaga (2008). Menurut Gagne (1992), media adalah berbagai jenis komponen dalam lingkungan siswa yang dapat merangsangnya untuk belajar. Senada dengan pendapat Gagne, Briggs mendefinisikan media pembelajaran sebagai bentuk fisik yang dapat menyajikan pesan yang dapat merangsang siswa untuk belajar. Dari dua definisi ini tampak pengertian media mengacu pada penggunaan alat yang berupa benda untuk membantu proses penyampaian pesan. Sementara itu Asosiasi Pendidikan Nasional (Nation Education Association/ NEA) memberikan batasan tentang media yaitu bentuk-bentuk komunikasi baik tercetak maupun audi visual serta bebagai peralatannya. Media pendidikan adalah sumber belajar dan dapat juga diartikan dengan manusia dan benda atau peristiwa yang membuat kondisi siswa mungkin memperoleh pengetahuan, keterampilan atau sikap.

development life cycle. Penelitian ini menggunakan metode MDLC (Multimedia Development Life Cycle) dengan enam tahapan yaitu concept (pengonsepan), design (perancangan), material collecting (pengumpulan bahan), assembly (pembuatan), testing (pengujian), dan distribution (pendistribusian). Penelitian ini menyimpulkan bahwa multimedia pembelajaran interaktif berbasis multimedia yang dirancang secara menarik akan membangkitkan motivasi dan rangsangan kegiatan belajar peserta didik, membantu peserta didik meningkatkan pemahaman materi pembelajaran serta menumbuhkan kreativitas belajar sehingga akan berdampak pada peningkatan kualitas pembelajaran.

\section{KAJIAN TEORI}

A. Pembelajaran

Kata media berasal dari bahasa latin medius yang secara harfiah berarti "tengah", "perantara", atau "pengantar". Dalam bahasa Arab, media adalah perantara atau pengantar pesan dari pengirim kepada penerima pesan Arsyad (2011). Pada pengertian lain, media adalah segala sesuatu yang dapat digunakan untuk menyampaikan pesan dari pengirim ke

\section{B. Multimedia Development Life Cycle (MDLC)}

Pengembangan metode media pembelajaran multimedia interaktif ini dilakukan berdasarkan 6 tahap, yaitu, concept (pengonsepan), design (perancangan), material Collecting (pengumpulan bahan), assembly (pembuatan), testing (pengujian) dan distribution (pendistribusian). Menurut (Binanto,I, 2010), ke enam tahapan ini tidaklah ahrus berurutan dalam praktiknya, tahap-tahap tersebut dapat saling bertukar posisi, meskipun demikian, tahap concept memang harus menjadi hal pertama kali dikerjakan.

\section{Teori Belajar Humanistik}

Pengertian Belajar Menurut Teori Humanistik Menurut teori humanistik, proses belajar harus dimulai dan ditujukan untuk kepentingan memanusiakan manusia itu sendiri. Oleh sebab itu, teori belajar humanistik sifatnya lebih abstrak danlebih mendekati bidang kajian filsafat, teori kepribadian dan psikoterapi, daripada bidang kajian psikologi belajar. Teori humanistic sangat mementingkan isi yang dipelajari daripada proses belajar itu sendiri. Teori belajar ini lebih banyak berbicara tentang konsep-konsep pendidikan untuk 
e-ISSN: 2685-7006 | p-ISSN: 2252-9063

Kumpulan Artikel Mahasiswa Pendidikan Teknik Informatika

(KARMAPATI)

Volume 10, Nomor 3,Tahun 2021

membentuk manusia yang dicita-citakan, serta tentang proses belajar dalam bentuknya yang paling ideal. Dengan kata lain, teori ini lebih tertarik pada pengertian belajar dalam bentuknya yang paling ideal daripada pemahaman tentang proses belajar sebagaimana apa adanya, seperti yang selama ini dikjaji oleh teori-teori belajar lainnya.

\section{Struktur Pernapasan Pada Manusia}

Pernapasan atau bisa disebut juga dengan respirasi adalah sebuah proses pengambilan oksigen dan pelepasan karbohidrat dan penggunaan energi yang ada di dalam tubuh. Bahkan ketika kita tertidur sekalipun. Pernapasan dibedakan menjadi dua yaitu pernapasan luar dan pernapasan dalam. Pernapasan luar adalah di mana terjadinya pertukaran udara di dalam alveolus dengan darah yang berada di dalam kapiler. Sedangkan pernapasan dalam adalah di mana terjadinya pernapasan antara darah yang ada di dalam kapiler dengan semua sel-sel yang ada di dalam tubuh.

Dalam bernapas, umumnya manusia membutuhkan 300 liter oksigen dalam sehari. Jika seseorang tersebut sedang mengerjakan pekerjaan berat seperti olahraga maka kebutuhan oksigennya menjadi bertambah berkali kali lipat. Jumlah oksigen yang diambil ini tergantung dari jenis aktivitas yang dilakukan, ukuran tubuh dan jenis makanan yang dikonsumsi.

\section{E. Sistem Ekskresi Pada Manusia}

Sistem ekskresi adalah sistem dengan tugas untuk mengolah zat sisa metabolisme dan racun, lalu membuangnya dari dalam tubuh. Sebab, zat-zat sisa dan racun tersebut bisa mengakibatkan masalah kesehatan apabila tidak dibuang dari dalam tubuh.

Pada sistem ekskresi manusia, terdapat sejumlah organ yang bekerja untuk tujuan tersebut. Organ-organ tersebut adalah kulit, paru-paru, hati, dan ginjal. Masing-masing organ memiliki fungsi serta cara kerja yang berbeda-beda untuk menyingkirkan zat sisa metabolisme dan racun dari dalam tubuhmu.

\section{METODOLOGI PENELITIAN}

Penelitian ini merupakan jenis penelitian pengembangan media pembelajaran pada materi struktur pernapasan dan ekskresi pada manusia. Multimedia yang dihasilkan diuji validitas terlebih dahulu oleh ahli media pembelajaran, ahli isi materi pembelajaran, dan guru kelas, setelah media dinyatakan telah dapat diujicobakan kepada siswa maka diadakan uji respon siswa.

\section{A. Desain Penelitian}

Pengembangan media pembelajaran multimedi pada kelas XI mata pelajaran biologi dengan materi "Struktur pernapasan dan Sistem Ekskresi Pada Manusia" di SMA NEGERI 2 SINGARAJA". menggunakan model MDLC (Multimedia Development Life Cycle) media pembelajaran interaktif ini dilakukan berdasarkan 6 tahap, yaitu, concept (pengonsepan), design (perancangan), material Collecting (pengumpulan bahan), assembly (pembuatan), testing (pengujian) dan distribution (pendistribusian). Menurut Binanto (2010), ke enam tahapan ini tidaklah ahrus berurutan dalam praktiknya, tahap-tahap tersebut dapat saling bertukar posisi, meskipun demikian, tahap concept memang harus menjadi hal pertama kali dikerjakan.

B. Tempat dan Waktu Penelitian

Penelitian ini dilaksanakan di SMA N 2 Singaraja yang diadakan pada tahun pelajaran 2020/2021.

C. Populasi dan Sampel Penelitian

Populasi dalam penelitian ini adalah seluruh siswa kelas XI IPA VII SMA N 2 Singaraja dan Sampel pada penelitian ini adalah seluruh kelas XI IPA VII SMA N 2 Singaraja.

D. Prosedur Penelitian

Prosedur penelitian pengembangan media pembelajaran multimedia pada kelas XI Mata pelajaran Biologi dengan materi "Struktur Pernapasan dan Sistem Ekskresi Pada Manusia" di SMA Negeri 2 Singaraja terdiri dari 6 tahap yakni concept (pengonsepan), design (perancangan), material Collecting 
e-ISSN: 2685-7006 | p-ISSN: $2252-9063$

Kumpulan Artikel Mahasiswa Pendidikan Teknik Informatika

(KARMAPATI)

Volume 10, Nomor 3,Tahun 2021

KARMAPATI

(pengumpulan bahan), assembly (pembuatan), testing (pengujian) dan distribution (pendistribusian).

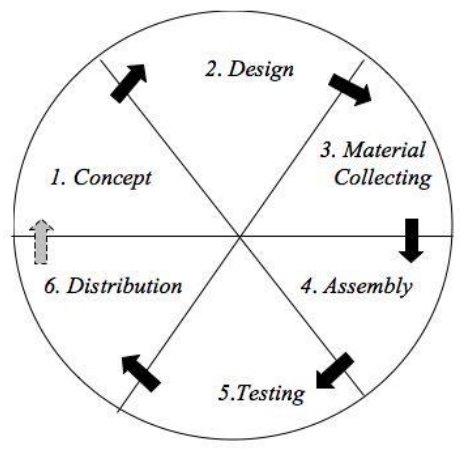

Gambar 1. Tahapan penelitian

Sumber: (Pangestu et al., 2019)

E. Instrumen Penelitian

Instrumen penelitian ini dengan memberikan kuesioner kepada ahli materi pelajaran yang terdiri dari dua orang, ahli media pembelajaran terdiri dari dua orang, dan uji respon siswa.

\section{F. Uji Validita Media Pembelajaran}

1. Uji Ahli Isi Materi

Uji ahli isi dipergunakan sebagai standar untuk mengetahui kesesuaian isi materi dari media pembelajaran, agar sesuai dengan kriteria dan kebutuhan dari pengguna / peserta didik. Peneliti melibatkan 2 guru yang mengajar mata pelajaran BIologi sebagai ahli untuk mengetahui secara detail kegiatan pembelajaran yang dilakukan. Instrument uji ahli isi materi dari media pembelajaran dapat dilihat pada bagian lampiran.

Penilaian hasil dari uji ahli isi materi dihitung menggunakan Rumus Gregory. Gregory mengembangkan teknik dalam pengujian isi yang sudah dikuantitatifkan. Mekanisme perhitungan pengujian validitas isi menurut Gregory ialah sebagai berikut.
- Para pakar yang dipercaya menilai instrument melakukan penilaian instrument perbutir.

- Pengelompokan skala, sesuai dan tidak sesuai.

- Hasil penilaian para pakar ditabulasi silang, misalnya untuk dua penilai.

Tabel 1. Contoh Tabulasi Penilainan Ahir

\begin{tabular}{|c|c|c|c|}
\cline { 3 - 4 } \multicolumn{2}{c|}{} & \multicolumn{2}{c|}{ Peneliti 1 } \\
\cline { 3 - 4 } \multicolumn{2}{c|}{} & $\begin{array}{c}\text { Tidak } \\
\text { Relevan }\end{array}$ & Relevan \\
\hline \multirow{3}{*}{$\begin{array}{c}\text { Peneliti } \\
2\end{array}$} & $\begin{array}{c}\text { Tidak } \\
\text { Relevan }\end{array}$ & (A) & (B) \\
\cline { 2 - 4 } & Relevan & (C) & (D) \\
\hline
\end{tabular}

Perhitungan validitas isi dengan rumus

Validitas Isi $=$

$\frac{D}{A+B+C+D}$

$\cdots$

Keterangan:

$\mathrm{A}=$ Sel yang menunjukkan ketidaksetujuan antara kedua penilai

$\mathrm{B}$ dan $\mathrm{C}=$ Sel yang menunjukkan perbedaan pandangan antara penilai

$\mathrm{D} \quad=$ Sel yang menunjukkan persetujuan valid antara kedua penilai.

Untuk melihat tingkat pencapaian kriteria validitas Uji Ahli

Tabel 2. Kriteria validitas uji ahli

\begin{tabular}{|c|c|}
\hline Koefisien Validitas & Tingkat Validitas \\
\hline $0,91-1,00$ & Sangat Tinggi \\
\hline $0,71-0,90$ & Tinggi \\
\hline $0,41-0,79$ & Cukup \\
\hline $0,21-0,40$ & Rendah \\
\hline $0,00-0,20$ & Sangat Rendah \\
\hline
\end{tabular}


e-ISSN: 2685-7006|p-ISSN: $2252-9063$

Kumpulan Artikel Mahasiswa Pendidikan Teknik Informatika

(KARMAPATI)

Volume 10, Nomor 3,Tahun 2021

\section{Uji Ahli Isi Media}

Uji ahli media berfungsi sebagai dasar acuan untuk mengetahui kesesuaian secara teknis pada pembuatan media pembelajaran secara visual dan fungsionalitas media pembelajaran yang dibuat. Dimana melibatkan 2 dosen yang ahli dalam bidang media pembelajaran. Penilaian hasil dari uji ahli desain dan media pembelajaran dihitung dengan Rumus Gregory (Gregogy, 2000). Instrument uji ahli media pembelajaran Bioligi dapat dilihat pada bagian lampiran.

Penilaian hasil dari uji ahli isi materi dihitung dengan Rumus Gregory. Gregory mengembangkan teknik dalam pengujian isi yang sudah dikuantitatifkan. Mekanisme perhitungan pengujian validitas isi menurut Gregory ialah sebagai berikut:

- Para pakar yang dipercaya menilai instrument melakukan penilaian instrument perbutir.

- Pengelompokan skala, sesuai dan tidak sesuai.

Hasil penilaian para pakar ditabulasi silang, misalnya untuk dua penilai.

Tabel 3. Contoh Tabulasi Penilaian Akar

\begin{tabular}{|c|c|c|c|}
\cline { 3 - 4 } \multicolumn{2}{c|}{} & \multicolumn{2}{c|}{ Peneliti 1 } \\
\cline { 3 - 4 } \multicolumn{2}{c|}{} & $\begin{array}{c}\text { Tidak } \\
\text { Relevan }\end{array}$ & Relevan \\
\hline \multirow{3}{*}{$\begin{array}{c}\text { Peneliti } \\
2\end{array}$} & $\begin{array}{c}\text { Tidak } \\
\text { Relevan }\end{array}$ & (A) & (B) \\
\cline { 2 - 4 } & Relevan & (C) & (D) \\
\hline
\end{tabular}

Perhitungan validitas isi dengan rumus

Validitas Isi $=\frac{D}{\mathbf{A}+\mathbf{B}+\mathbf{C}+\mathbf{D}}=\ldots \ldots \ldots \ldots \ldots \ldots \ldots$

Keterangan:

$\mathrm{A} \quad=$ Sel yang menunjukkan ketidaksetujuan antara kedua penilai

$$
p=\frac{f}{n} \times 100 \%
$$

$\mathrm{B}$ dan $\mathrm{C}=$ Sel yang menunjukkan perbedaan pandangan antara penilai

$\mathrm{D}=$ Sel yang menunjukkan persetujuan valid antara kedua penilai.

Untuk melihat tingkat pencapaian kriteria validitas Uji Ahli.

Tabel 4. Kriteria validitas uji ahli

\begin{tabular}{|c|c|}
\hline Koefisien Validitas & Tingkat Validitas \\
\hline $0,91-1,00$ & Sangat Tinggi \\
\hline $0,71-0,90$ & Tinggi \\
\hline $0,41-0,79$ & Cukup \\
\hline $0,21-0,40$ & Rendah \\
\hline $0,00-0,20$ & Sangat Rendah \\
\hline
\end{tabular}

\section{Uji Respon Siswa}

Uji respon siswa dilakukan untuk mengetahui kepuasan siswa terhadap media pembelajaran. Uji respon siswa dilakukan dengan cara menyebarkan angket kepada siswa yang telah menyaksikan media pembelajaran Biologi. Dalam pengisian angket responden akan didampingi langsung oleh peneliti. Instrumen uji respon penonton media pembelajaran Biologi dapat dilihat pada bagian lampiran . Metode pengukuran menggunakan skala Likert, angket uji dibuat dalam bentuk checklist dengan lima gradasi pilihan ialah Sangat Setuju (SS), Setuju (S), Kurang Setuju (KS), Tidak Setuju (TS) dan Sangat Tidak Setuju (STS).

Tabel 5. Skor angket uji respon siswa

\begin{tabular}{|l|c|c|}
\multicolumn{1}{|c|}{ Alternatif } & $\begin{array}{c}\text { Skor } \\
\text { Positif }\end{array}$ & $\begin{array}{c}\text { Skor } \\
\text { Negatif }\end{array}$ \\
\hline Sangat Setuju (SS) & 5 & 1 \\
\hline Setuju (S) & 4 & 2 \\
\hline Kurang Setuju (CS) & 3 & 3 \\
\hline Tidak Setuju (TS) & 2 & 4 \\
\hline $\begin{array}{l}\text { Sangat Tidak Setuju } \\
\text { (STS) }\end{array}$ & 1 & 5 \\
\hline
\end{tabular}

Penilaian kelayakan pada angket uji menggunakan persentase. Menghitung persentase setiap subyek digunakan rumus (sugiyono, 2011): 
e-ISSN: 2685-7006 | p-ISSN: 2252-9063

Kumpulan Artikel Mahasiswa Pendidikan Teknik Informatika

(KARMAPATI)

Volume 10, Nomor 3,Tahun 2021

Keterangan:

$$
\begin{array}{ll}
p & =\text { Persentase } \\
f & =\text { Frakuensi dari setiap jawaban }
\end{array}
$$

angket / jumlah total

$$
\begin{array}{ll}
n & =\text { Jumlah skor ideal } \\
100 & =\text { Bilangan tetap }
\end{array}
$$

Untuk melihat kriteria atau tingkat pencapaian media pembelajaran persentase yang telah diperoleh kemudian ditransformasikan ke dalam kalimat seperti kriteria yang ditunjukkan pada tabel dibawah

Tabel 6. Kriteria angket uji respon siswa

\begin{tabular}{|c|c|l|l|}
\hline No & Interval & Kualiikasi & Keterangan \\
\hline 1 & $\begin{array}{c}90 \%- \\
100 \%\end{array}$ & $\begin{array}{l}\text { Sangat } \\
\text { Baik }\end{array}$ & $\begin{array}{l}\text { Tidak perlu } \\
\text { direvisi }\end{array}$ \\
\hline 2 & $\begin{array}{c}75 \%- \\
89 \%\end{array}$ & Baik & $\begin{array}{l}\text { Tidak perlu } \\
\text { direvisi }\end{array}$ \\
\hline 3 & $65 \%-$ & Cukup & Direvisi \\
\hline 4 & $55 \%$ & & \\
\hline 5 & $64 \%$ & Kurang & Direvisi \\
\hline & $54 \%$ & Kurang & Direvisi \\
\hline
\end{tabular}

\section{HASIL DAN PEMBAHASAN}

\section{A. HASIL}

Hasil pengujian "Pengembangan Media Pembelajaran Struktur Pernapasan Dan Ekskresi Manusia Untuk Kelas XI IPA Di SMA Negeri 2 Singaraja" terdapat uji ahli isi, uji ahli media dan uji respon (siswa).

1. Uji Ahli Isi

Uji ahli isi dipergunakan sebagai standar untuk mengetahui kesesuaian isi materi dari materi pembelajaran Biologi mengenai struktur pernapasan dan ekskresi manusia, agar sesuai dengan kriteria dan kebutuhan dari pengguna/peserta didik. Hasil implementasi instrumen uji ahli isi materi dari media pembelajaran dapat dilihat pada bagian lampiran. Berikut merupakan hasil validitas dari implementasi uji ahli isi materi menggunakan rumus pengujian Gregory:

Uji validitas isi instrumen ahli materi dilakukan dengan penilaian pakar, dalam hal ini dilibatkan dua orang pakar, yaitu satu orang dosen dari Jurusan Pendidikan Biologi Undiksha dan satu guru bidang Studi Biologi.

\begin{tabular}{|c|c|c|c|}
\hline & \multicolumn{2}{|c|}{ Peneliti 1} \\
\hline & & $\begin{array}{c}\text { Tidak } \\
\text { Relevan }\end{array}$ & Relevan \\
\hline \multirow{3}{*}{$\begin{array}{c}\text { Peneliti } \\
2\end{array}$} & Tidak & (A) & (B) \\
\hline & Relevan & 0 & 0 \\
\hline & Relevan & $\begin{array}{c}\text { (C) } \\
0\end{array}$ & $\begin{array}{l}\text { (D) } \\
11\end{array}$ \\
\hline Validitas is & D & 11 & $=11=1$ \\
\hline
\end{tabular}

Penilai 1: I Made Oka Riawan, S.Pd., M,Sc. Penilai 2: Drs. I Ketut Sara Udaya

Tabel 7. Tabulasi silang $2 \times 2$ Ahli Isi

Jadi, koefisien validitas isi instrument evaluasi ahli materi terhadap media pembelajaran Pada Kelas XI Mata Pelajaran Biologi dengan materi struktur pernapasan dan ekskresi manusia adalah 1 dibulatkan menjadi 1 . Kesimpulannya, tingkat validitas isi instrument evaluasi ahli materi adalah sangat tinggi sehingga dinyatakan layak untuk digunakan.

2. Uji Ahli Media

Uji ahli media difungsikan sebagai dasar acuan untuk mengetahui kesesuaian secara teknis pada pembuatan media pembelajaran, secara visual dan fungsionalitas media pembelajaran yang dibuat. Hasil implementasi instrumen uji ahli isi materi dari media pembelajaran Biologi dapat dilihat pada bagian lampiran. Berikut merupakan hasil validitas dari implementasi uji ahli isi materi menggunakan rumus pengujian Gregory: 
e-ISSN: 2685-7006 | p-ISSN: 2252-9063

Kumpulan Artikel Mahasiswa Pendidikan Teknik Informatika

(KARMAPATI)

Volume 10, Nomor 3,Tahun 2021

Uji validitas media dilakukan dengan penilaian pakar, dalam hal ini dilibatkan dua orang pakar, yaitu dua orang dosen dari Program Studi Pendidikan Teknik Informatika, Undiksha.

Penilai 1 : Luh Putu Eka Damayanti, S.Pd., M.Pd

Penilai 2 : I Gede Partha Sindu, S.Pd., M.Pd

Tabel 8. Tabulasi silang 2 × 2 Ahli Media

\begin{tabular}{|c|c|c|c|}
\cline { 3 - 4 } \multicolumn{2}{c|}{} & \multicolumn{2}{c|}{ Peneliti 1 } \\
\cline { 3 - 4 } \multicolumn{2}{c|}{} & $\begin{array}{c}\text { Tidak } \\
\text { Relevan }\end{array}$ & Relevan \\
\hline \multirow{3}{*}{$\begin{array}{c}\text { Peneliti } \\
2\end{array}$} & Tidak & $($ A) & $($ B) \\
\cline { 3 - 4 } & Relevan & 0 & 0 \\
\cline { 2 - 4 } & Relevan & $($ C) & (D) \\
& & 0 & 11 \\
\hline
\end{tabular}

$$
\text { Validitas is }=\frac{D}{A+B+C+D}=\frac{13}{O+0+2+13}=13=0.86666666667
$$

Jadi, koefisien validitas isi instrument evaluasi ahli materi terhadap media pembelajaran Pada Kelas XI Mata Pelajaran Biologi dengan materi struktur pernapasan dan ekskresi manusia adalah 0,8666666667 dibulatkan menjadi 0,87 . Kesimpulannya, tingkat validitas isi instrument evaluasi ahli materi adalah sangat tinggi sehingga dinyatakan layak untuk digunakan.

3. Uji Respon Siswa

Uji respon siswa dilakukan untuk mengetahui kepuasan siswa terhadap media pembelajaran interaktif. Uji respon siswa dilakukan dengan cara menyebarkan 26 angket ke 26 siswa kelas XI MIPA VII yang telah menyaksikan media pembelajaran Biologi Dengan Materi "Struktur Pernapasan dan Ekskresi Manusia". Dalam pengisian angket, responden akan didampingi langsung oleh peneliti.
Metode pengukuran menggunakan skala Likert, angket uji dibuat dalam bentuk checklist dengan lima gradasi pilihan, yaitu Sangat Setuju (SS), Setuju (S), Kurang Setuju (KS), Tidak Setuju (TS) dan Sangat Tidak Setuju (STS). Berikut merupakan implementasi hasil uji respon siswa Uji respon dilakukan oleh siswa sebanyak 26 respon adalah 4.103846154 dan dibulatkan menjadi 4.10. Kemudian dilakukan pengubahan terhadap rata - rata tersebut menjadi hasil persentase agar sesuai dengan tabel kriteria uji respon siswa, untuk mengubah menjadi \% : Rata Rata 4,10/ 5 x $100=$ 82\%. Jadi, berdasarkan data respon siswa terhadap media pembelajaran pada kelas XI Mata Pelajaran Biologi Dengan Materi "Struktur Pernapasan dan Ekskresi Manusia" di SMA Negeri 2 Singaraja adalah $\mathbf{8 2 \%}$ sudah memenuhi kriteria BAIK.

Tabel 9. Kisi-kisi Angket Uji Respon siswa

\begin{tabular}{|l|l|}
\hline \multicolumn{1}{|c|}{ Indikator } & \multicolumn{1}{c|}{ Butir Penilaian } \\
\hline $\begin{array}{l}\text { Kesesuaian } \\
\text { Penyajian Media }\end{array}$ & $1,2,3,4$ \\
\hline Ketertarikan & $5,6,7,8,12,14$ \\
\hline Gemifikasi & $9,11,13$ \\
\hline Pemahaman Materi & $10,15,16$ \\
\hline Kemandirian Belajar & $17,18,19,20$ \\
\hline
\end{tabular}

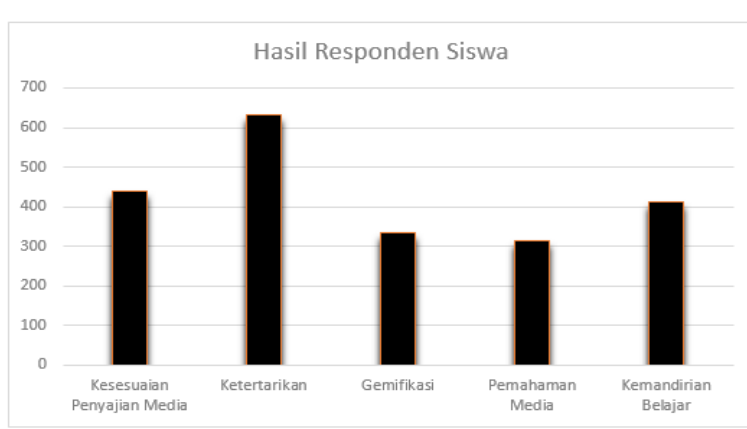

Gambar 2. Hasil Uji Respon Siswa

\section{B. PEMBAHASAN}

Pengembangan media pembelajara ini memiliki tujuan untuk membantu proses pembelajaran, media pembelajaran diharapkan 
e-ISSN: 2685-7006|p-ISSN: 2252-9063

Kumpulan Artikel Mahasiswa Pendidikan Teknik Informatika

(KARMAPATI)

Volume 10, Nomor 3,Tahun 2021

dapat meningkatkan pemahaman terhadap materi biologi selama proses belajar mengajar di kelas. Salah satu upaya untuk dapat mencapai proses ini adalah dengan adanya suatu media pembelajaran yang meningkatkan motivasi dan menarik perhatian siswa untuk belajar, sehingga dapat memaksimalkan proses penyampaian materi. Sebuah media pembelajaran biologi dengan materi struktur pernapasan dan ekskresi manusia, sangat di butuhkan di sekolah karena dapat menjadi media yang dapat membantu guru dalam menyampaikan materi pembelajaran. Dalam perancangan media ini menggabungkan dua media atau lebih seperti teks, grafik, gambar, audio, video, dan animasi secara terpadu yang di akhir pembelajaran terdapat tes yang akan mengulang materi sehingga siswa dapat memahami dengan jelas materi yang dijelaskan diawal.

Pengembangan media pembelajaran struktur pernapasan dan ekskresi manusia merupakan sebuah pengembangan dengan menggunakan metode $M D L C$. Metode $M D L C$ dipengembangan ini, terdiri dari 6 tahapan, yaitu Concept (pengonsepan), Design (perancangan), Material Collecting (pengumpulan bahan), Assembly (pembuatan), Testing (pengujian) dan Distribution (distribusi). Tahap-tahap pengembangannya yang sederhana, ringkas, padat dan bahkan antara tahapan Design dan Assembly dapat dilakukan paralel.

Hasil penilaian ahli isi media pempbelajaran menggunakan uji Gregory berdasarkan angket menunjukkan bahwa tingkat pencapaian dari media pembelajaran adalah "Sangat Tinggi" dan layak untuk dilanjutkan. Hal tersebut mengindikasikan bahwa materi pelajaran yang diimplementasikan dalam media pembelajaran sudah relevan untuk digunakan dalam pembelajaran. Materi pelajaran yang memadukan sajian materi dari beberapa sumber buku sebagai referensi pembelajaran dinyatakan sudah sesuai dengan indikator dan tujuan pembelajaran.

Setelah melalui tahap pengujian para ahli, didapatkan hasil uji ahli isi materi pembelajaran dengan hasil perhitungan 1,00 menunjukkan kriteria "Sangat Tinggi" dan hasil uji ahli media dengan hasil perhitungan 0.87 menunjukkan pada kriteria "Tinggi". Rata-rata hasil perhitungan uji ahli mendapatkan hasil 1,00 \& 0.87 menunjukkan pada kriteria "Valid". Menurut (Sugiyono, 2010), validitas produk dapat dilakukan oleh beberapa pakar atau tenaga ahli yang sudah berpengalaman untul menilai kelemahan dan kekuatan produk yang dihasilkan agar suatu produk dapat digunakan sesuai dengan tujuannya.

Selanjutnya dilakukan uji respon siswa, responden yang digunakan sebanyak 26 orang siswa kelas XI MIPA VII SMA Negeri 2 Singaraja memperoleh rata-rata dari semua responden mendapatkan hasil 4.10 Kemudian peneliti mengubah rata - rata tersebut menjadi hasil persentase agar sesuai dengan tabel kriteria uji respon siswa. Setelah dikonversi ke dalam persentasi didapatkan hasil $82 \%$. Jika dikategorikan ke dalam tabel konversi termasuk dalam kategori "Baik". Hal ini menunjukkan keberhasilan media pembelajaran pada Mata Pelajaran Biologi Dengan Materi "Struktur Pernapasan dan Ekskresi Manusia" di SMA Negeri 2 Singaraja dengan baik, yang dibuktikan dengan terbantunya siswa dalam proses pembelajaran, mempermudah proses guru membawakan materi pembelajaran, siswa tidak cepat merasa jenuh saat pembelajaran, dan diharapkan bisa meningkatkan motivasi siswa dalam pembelajaran Biologi.

Selanjutnya dilakukan uji efektivitas dari media pembelajaran. Dalam uji efektivitas peneliti menggunakan hasil dari perhitungan uji respon siswa. Uji respon dilakukan kepada 26 orang siswa dengan hasil penelitian sebanyak $82 \%$ yang jika dikonversikan ke dalam tabel kriteria efektivitas media pembelajaran berada pada kriteria "Efektif". Dari hasil ini menunjukkan bahwa media pembelajaran Biologi efektif untuk diterapkan dalam pembelajaran.

Pengembangan media pembelajaran struktur pernapasan dan ekskresi manusia untuk SMA Negeri 2 Singaraja memiliki beberapa 


\section{e-ISSN: 2685-7006 | p-ISSN: 2252-9063 \\ Kumpulan Artikel Mahasiswa Pendidikan Teknik Informatika \\ (KARMAPATI) \\ Volume 10, Nomor 3,Tahun 2021}

kelebihan yang ditemukan selama proses pembuatannya. Adapun kelebihan dari media pembelajaran berkonsep gamifikasi ini adalah: (1) media yang dibuat sesuai dengan karakteristik siswa, (2) fleksibilitas dari media pembelajaran memudahkan guru dalam melakukan proses pembelajaran dikelas, (3) materi yang berbentuk animasi video membuat siswa merasa senang dalam proses belajar, (4) adanya media pembelajaran ini membuat suasana dalam kelas menjadi riang dan gembira.

\section{KESIMPULAN DAN SARAN}

Berdasarkan hasil penelitian dan pembahasan pada penelitian Pengembangan media pembelajaran pada kelas XI Mata Pelajaran Biologi Dengan Materi "Struktur Pernapasan dan Ekskresi Manusia" di SMA Negeri 2 Singaraja maka penulis dapat menarik kesimpulan sebagai beriku. respon pengguna yaitu guru dan peserta didik media pembelajaran pada kelas XI Mata Pelajaran Biologi Dengan Materi "Struktur Pernapasan dan Ekskresi Manusia" di SMA Negeri 2 Singaraja mendapatkan respon yang baik, mereka sangat tertarik dan antusias untuk melihat dan mempelajari materi Struktur Pernapasan dan Ekskresi Manusia ini dengan cara menonton media pembelajaran yang di tampilkan. Uji respon siswa mendapatkan rata-rata yaitu $82 \%$. Pengembangan media pembelajaran berkonsep Struktur Pernapasan dan Ekskresi Manusia mata pelajaran Biologi kelas XI di SMA Negeri 2 Singaraja mampu menjadi sumber belajar bagi siswa. Media pembelajaran digunakan sebagi panduan belajar siswa, sehingga dapat meningkatkan konsentrasi dan fokus pada siswa serta membantu proses belajar siswa di sekolah. Ini dibuktikan dengan hasil respon siswa yaitu $82 \%$ jika dikonversi kedalam tabel siswa termasuk dalam kategori Baik.

Berdasarkan pengamatan peneliti di lapangan, terdapat beberapa hal yang dapat dijadikan bahan pertimbangan untuk pengembangan berikutnya. Pengembangan media pembelajaran struktur pernapasan dan ekskresi manusia ini masih banyak hal-hal yang perlu adanya konten interaktif yang bisa mengatur kognitif siswa pada kegiatan belajar. Media ini masih memiliki keterbatasan pada materi sehingga untuk pengembangan selanjutnya materi struktur pernapasan dan ekskresi manusia dapat diperdalam sehingga memberikan pengetahuan yang lebih dalam untuk pelajaran Biologi. Pengembangan media pembelajaran struktur pernapasan dan ekskresi manusia ini masih banyak hal-hal yang perlu ditambahkan seperti fitur-fitur yang menarik.

Pengembangan media pembelajaran struktur pernapasan dan ekskresi manusia untuk SMA Negeri 2 Singaraja memiliki beberapa kelebihan yang ditemukan selama proses pembuatannya. Adapun kelebihan dari media pembelajaran berkonsep gamifikasi ini adalah: (1) media yang dibuat sesuai dengan karakteristik siswa, (2) fleksibilitas dari media pembelajaran memudahkan guru dalam melakukan proses pembelajaran dikelas, (3) materi yang berbentuk animasi video membuat siswa merasa senang dalam proses belajar, (4) adanya media pembelajaran ini membuat suasana dalam kelas menjadi riang dan gembira.

\section{REFERENSI}

Binanto, Iwan. 2010. Multimedia Dasar-Dasar Teori dan pengembangannya. Yogyakarta:ANDI.

Gregogy, R. J. (2000). Phsycological Testing. United States of America: Allyn \& Bacon Inc.

Irnaningtyas, Yossa Istiadi. 2017. Buku Biologi SMA kelas XI. Bandung: Erlangga.

Sugiarto, Hari. 2018. "Penerapan Multimedia Development Life Cycle Pada Aplikasi Pengenalan Abjad Dan Angka" 3 (1): 2631.

Sugiyono. 2009. Motode Penlitian Kuantitatif, Kualitatif, Dan R\&D. Bandung: CV. Alfabeta. 
e-ISSN: 2685-7006|p-ISSN: $2252-9063$

Kumpulan Artikel Mahasiswa Pendidikan Teknik Informatika

(KARMAPATI)

KดRMAPดTI

Volume 10, Nomor 3,Tahun 2021

Wiratama, Anggar, Jasson Prestiliano, and George Nikijuluw. 2015. "Penerapan Konsep Gamification Untuk Meningkatkan Minat Dan Partisipasi Siswa Pada Mata Pelajaran Geografi Di Sma Negeri 2 Salatiga 1)." PendidikanTeknik Informatika Dan Komputer, 3.

Ni Nyoman Perni Dan Adi Widya. 2018. Penerapan Teori Belajar Humanistik Dalam Pembelajaran Volume. 3. Jurnal Pendidikan Dasar

Mustika, Eka Prasetya Adhy Sugara, Maissy Pratiwi. 2017. Pengembangan Media Pembelajaran Interaktif dengan Menggunakan Metode Multimedia Development Life Cycle Vol 2. No. 2.

https://eprints.uny.ac.id/62637/2/BAB\%20II.pd $\mathrm{f}$ 